\title{
Live birth outcomes from IVF treatments in younger patients with low $\mathrm{AMH}$
}

\author{
Maho Miyagi ${ }^{1}$, Keiko Mekaru ${ }^{1}$, Rie Nakamura ${ }^{1}$, Sugiko Oishi ${ }^{1}$, Kozue Akamine ${ }^{1}$, Chiaki Heshiki ${ }^{1}$, Yoichi Aoki ${ }^{1}$ \\ ${ }^{1}$ Department of Obstetrics and Gynecology, Graduate School of Medicine, University of the Ryukyus. Nishihara, \\ Okinawa, Japan
}

\begin{abstract}
Objective: Anti-Müllerian hormone $(A M H)$ is used to predict in vitro fertilization outcomes. However, predicting live birth is difficult in younger patients with low AMH. Thus, this study aimed to determine the live birth rates from younger patients with low anti-Müllerian hormone levels.
\end{abstract}

Methods: A total of 296 infertile patients with $\mathrm{AMH}$ measured (younger group, aged 25-38 years; older group, aged $39-42$ years) were included in this study. In vitro fertilization outcomes between patients with $\mathrm{AMH}$ levels of $<1.0 \mathrm{ng} / \mathrm{mL}$ and $\geq 1.0 \mathrm{ng} / \mathrm{mL}$ were compared.

Results: Younger patients with AMH levels <1.0ng/ $\mathrm{mL}$ (younger low AMH group) exhibited lower number of oocytes retrieved than patients with $\mathrm{AMH}$ levels $\geq 1.0 \mathrm{ng} /$ $\mathrm{mL}$ (younger normal AMH group). However, there were no significant differences in cumulative pregnancy or cumulative live birth rates between groups. Older patients with $\mathrm{AMH}$ levels $\geq 1.0 \mathrm{ng} / \mathrm{mL}$ (older normal $\mathrm{AMH}$ group) had significantly better outcomes as per mean number of oocytes, cumulative pregnancy rate, and cumulative live birth rate than older patients with $A M H$ levels $<1.0 \mathrm{ng} / \mathrm{mL}$ (older low AMH group). In the younger low AMH group, the frequency of oocyte retrieval was significantly higher in patients who achieved live birth. In addition, the blastocyst transfer rate was significantly higher in individuals with live births versus subjects with non-live births.

Conclusions: $\mathrm{AMH}$ is a predictor of live birth among older, but not younger, women. Our report suggests that younger women may become pregnant even with low AMH levels when they obtain blastocysts from frequent oocyte retrievals.

Keywords: anti-Müllerian hormone, in vitro fertilization, ovarian reserve, live birth, oocyte retrieval

\section{INTRODUCTION}

Anti-Müllerian hormone (AMH) is an accurate predictor of a woman's ovarian reserve. It has been used to predict the outcomes of assisted reproductive technology (ART) and to determine treatment regimens. AMH is secreted by granulosa cells in women, and its levels in blood reflect the number of secondary follicles, with decreases observed with aging (Tal et al., 2015). Although AMH levels also correlate with the number of developing follicles due to ovarian stimulation, predicting pregnancy and live births using AMH levels is difficult (Tal et al., 2015; La Marca et al., 2010). In younger patients in particular, live births may reportedly be achieved even with low AMH levels (Sefrioui et al., 2019). In general, patients with low AMH levels are difficult to treat because the number of oocytes retrieved is low (Baker, 2018; La Marca et al., 2007). Some reports indicate that AMH levels are not related to live birth or pregnancy rates (Tal et al., 2015; Hansen et al., 2016). This study aimed to determine the live birth rate in younger patients with low $\mathrm{AMH}$, and to further identify the factors tied to how live births were achieved in this group.

\section{MATERIAL AND METHODS}

A total of 296 infertile patients aged $25-42$ years were included in this study. Their AMH levels were measured at the time of first oocyte retrieval at our department between January 2015 and December 2017. Around 1077 cycles were recorded.

In vitro fertilization (IVF) outcomes in patients with an $\mathrm{AMH}$ level $<1.0 \mathrm{ng} / \mathrm{mL}$ and $\geq 1.0 \mathrm{ng} / \mathrm{mL}$ were evaluated retrospectively using our institution's databases and medical records of ART treatment. Patients were divided into two groups: the younger group (aged 25-38 years) and the older group (aged 39-42 years) (Fig. 1). ART methods included IVF and intracytoplasmic sperm injection, fresh embryo transfer, and thawed embryo transfer. The mean number of oocytes retrieved per oocyte pick-up cycle, the mean frequency of oocyte retrievals per patient, the cumulative pregnancy rate per patient, and the cumulative live birth rate per patient were compared and evaluated across the younger low (AMH $<1.0 \mathrm{ng} / \mathrm{mL}$ ), younger normal (AMH $\geq 1.0 \mathrm{ng} / \mathrm{mL}$ ), older low (AMH $<1.0 \mathrm{ng} / \mathrm{mL}$ ), and older normal (AMH $\geq 1$.0ng/mL) AMH groups.

For the ovulation induction method, a short protocol or antagonist protocol was utilized in the ovarian stimulation protocol of patients with normal ovarian function. A mild stimulation protocol, such as with clomiphene citrate and a natural cycle, was prescribed to patients with decreased ovarian function. AMH was examined using an electrochemiluminescence assay.

A $t$-test or Fisher's exact test was used in statistical analyses, and a $p$-value of $<0.05$ was considered statistically significant. Figure 1 illustrates the study design.

\section{RESULTS}

The mean age of the patients was 37.8 years, and the median AMH level was $1.5 \mathrm{ng} / \mathrm{mL}$. The pregnancy rate per embryo transfer in all patients was calculated as $28.2 \%$ (153/543 cycles), and the live birth rate per embryo transfer was $19.4 \%$ (106/543 cycles). The median AMH value was $0.61 \mathrm{ng} / \mathrm{mL}$ in the younger low $A M H$ group (range: $0.00-0.99 \mathrm{ng} / \mathrm{mL}$; high: $A M H>0.74 \mathrm{ng} / \mathrm{mL}$; medium: $0.50-$ $0.74 \mathrm{ng} / \mathrm{mL}$; and low: $A M H<0.50 \mathrm{ng} / \mathrm{mL}$ ) and $2.67 \mathrm{ng} / \mathrm{mL}$ in the younger normal $\mathrm{AMH}$ group (range: $1.00-23.00$ $\mathrm{ng} / \mathrm{mL}$; high: $A M H>5.00 \mathrm{ng} / \mathrm{mL}$; medium: $5.00-2.00 \mathrm{ng} /$ $\mathrm{mL}$; and low: $\mathrm{AMH}<2.00 \mathrm{ng} / \mathrm{mL}$ ). The median $\mathrm{AMH}$ level was $0.43 \mathrm{ng} / \mathrm{mL}$ in the older low $\mathrm{AMH}$ group (range: $0.00-0.99 \mathrm{ng} / \mathrm{mL}$; high: $\mathrm{AMH}>0.75 \mathrm{ng} / \mathrm{mL}$; medium: $0.75-$ $0.43 \mathrm{ng} / \mathrm{mL}$; and low: $A M H<0.43 \mathrm{ng} / \mathrm{mL}$ ) and $2.22 \mathrm{ng} / \mathrm{mL}$ in the older normal AMH group (range: $1.00-14.50 \mathrm{ng} / \mathrm{mL}$; high: $A M H>4 \mathrm{ng} / \mathrm{mL}$; medium: $2.00-4.00 \mathrm{ng} / \mathrm{mL}$; and low: $\mathrm{AMH}<2 \mathrm{ng} / \mathrm{mL}$ ).

Table 1 presents the IVF results for the younger low AMH group and the younger normal AMH group. Although the mean number of oocytes retrieved was significantly higher 


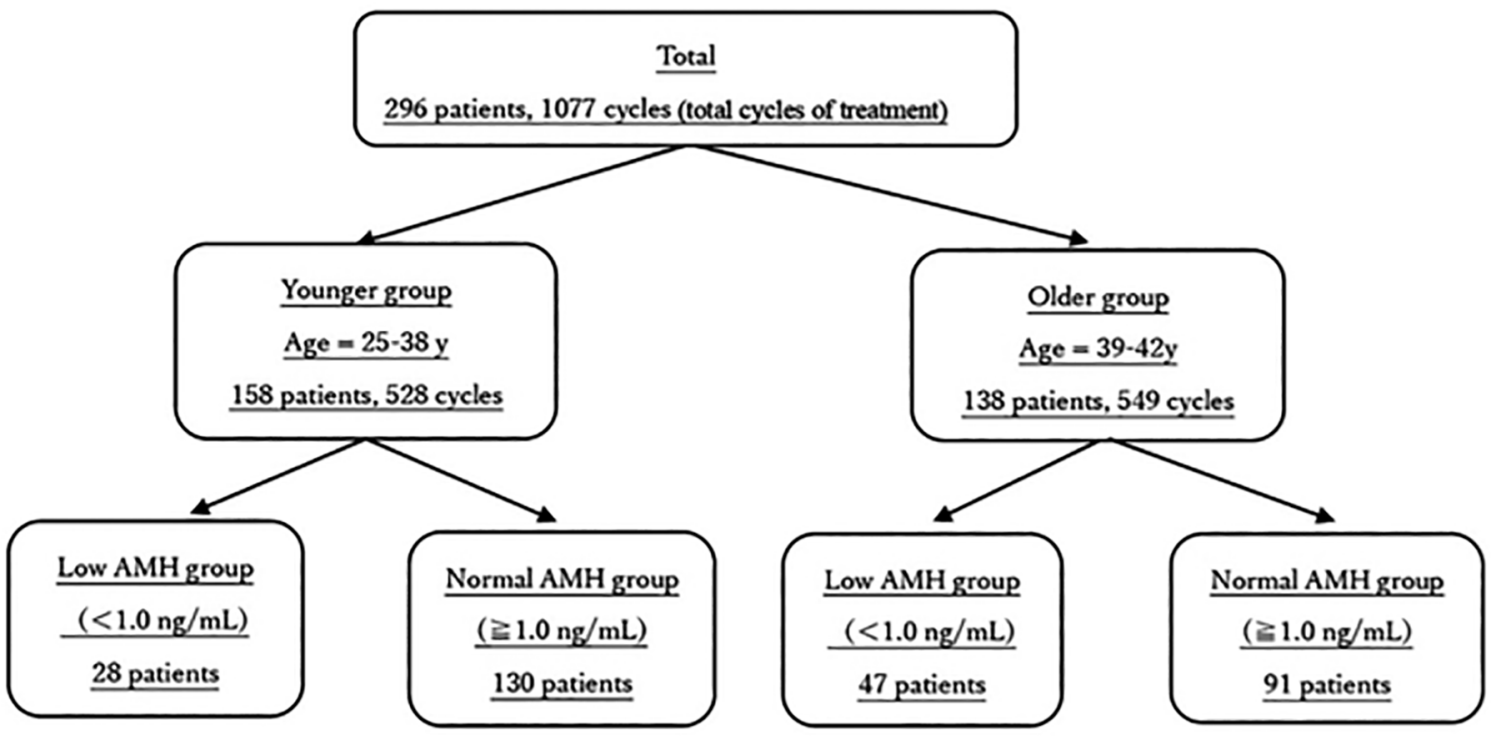

Figure 1. Flowchart of setting the target population.

Table 1. IVF outcomes in the younger low AMH and younger normal AMH groups.

\begin{tabular}{|c|c|c|c|}
\hline & $\begin{array}{c}\text { Younger Low } \\
\text { AMH group* } \\
\text { ( } n=128 \text { cycles) }\end{array}$ & $\begin{array}{c}\text { Younger Normal } \\
\text { AMH group** } \\
\text { ( } n=400 \text { cycles) }\end{array}$ & $\boldsymbol{p}$ \\
\hline Age $(y)$, mean $\pm S D$ & $35.2 \pm 0.48$ & $34.8 \pm 0.27$ & N.S. \\
\hline $\mathrm{AMH}(\mathrm{ng} / \mathrm{mL})$, mean $\pm \mathrm{SD}$ & $0.49 \pm 0.30$ & $4.17 \pm 0.17$ & $<0.0001$ \\
\hline Total doses of HMG/ FSH (IU) mean \pm SD & $1523.4 \pm 114.1$ & $1982 \pm 52.7$ & 0.0003 \\
\hline Estrogen value of before $\mathrm{hCG}(\mathrm{pg} / \mathrm{mL})$, mean \pm SD & $518 \pm 182.5$ & $1317 \pm 98.8$ & 0.0001 \\
\hline Progesterone value of before $\mathrm{hCG}(\mathrm{ng} / \mathrm{mL})$, mean $\pm \mathrm{SD}$ & $0.7 \pm 0.09$ & $0.6 \pm 0.05$ & N.S. \\
\hline No. of oocytes retrieved, mean $\pm S D$ & $2.8 \pm 1.63$ & $11.5 \pm 1.13$ & 0.0001 \\
\hline Frequency of oocyte retrievals per patient, mean \pm SD & $2.6 \pm 0.38$ & $1.3 \pm 0.18$ & 0.0001 \\
\hline Cumulative pregnancy rate per patient & $50 \%(14 / 28)$ & $65.9 \%(95 / 144)$ & N.S. \\
\hline Cumulative live birth rate per patient & $39.3 \%(11 / 28)$ & $50 \%(72 / 144)$ & N.S. \\
\hline
\end{tabular}

*Low AMH: AMH $<1 \mathrm{ng} / \mathrm{mL}$. **Normal AMH group: AMH $\geq 1 \mathrm{ng} / \mathrm{mL}$.

$\mathrm{AMH}=$ anti-Müllerian hormone; IVF=in vitro fertilization; N.S.=not significant.

in the younger normal AMH group than in the younger low AMH group, no significant differences in pregnancy or live birth rates per patient were noted. Mean total HMG doses and the average estradiol levels were significantly higher in the younger normal AMH group than in the younger low AMH group. In addition, the younger low $\mathrm{AMH}$ group exhibited a significantly higher mean frequency of oocyte retrievals per patient than the younger normal AMH group.

Table 2 shows the IVF results in the older low AMH group and older normal AMH group. The mean number of oocytes retrieved, pregnancy rate per patient, and live birth rate per patient were higher in the older normal $\mathrm{AMH}$ group. Similar to the findings on the younger groups, the mean total HMG dose and the average estradiol level were significantly higher in the older normal AMH group than in the older low AMH group.

Table 3 shows the comparisons between patients who had live births and the subjects unable to attain live births in the younger low AMH group. In the younger low $\mathrm{AMH}$ group, the mean frequency of oocyte retrievals per patient was statistically higher in patients with live births
(3.5) than in patients unable to achieve live births (2.1) $(p=0.035)$. In addition, the blastocyst transfer rate was significantly higher in the patients who achieved live births than in the ones who did not $(63.6 \%$ vs. $11.8 \%, p=0.010)$.

We further examined the blastocyst transfer rate by fresh and thawed embryo transfer cycles in a subset analysis. Table 3 shows the blastocyst transfer rates in the live birth and non-live birth groups further divided into fresh and thawed embryo transfer recipients in the younger low AMH group. In the fresh embryo transfer group, the blastocyst transfer rate was not significantly different between individuals with and without live births. However, in the thawed embryo transfer group, the blastocyst transfer rate was significantly higher in the live birth group than in the non-live birth group $(p=0.04)$.

\section{DISCUSSION}

To date, there has been no consensus on the relationship between $\mathrm{AMH}$ and pregnancy and live birth rates with ART, with some studies reporting correlations (Eldar-Geva et al., 2005; Nelson et al., 2007; Silberstein et al., 2006) 
Table 2. IVF outcomes in the older low group and older normal group.

\begin{tabular}{|c|c|c|c|}
\hline & $\begin{array}{c}\text { Older Low AMH } \\
\text { group* } \\
(\mathrm{n}=173 \text { cycles })\end{array}$ & $\begin{array}{c}\text { Older Normal } \\
\text { AMH group** } \\
\text { ( } \mathrm{n}=376 \text { cycles })\end{array}$ & $\boldsymbol{p}$ \\
\hline Age $(y)$, mean $\pm S D$ & $40.6 \pm 0.16$ & $40.7 \pm 0.11$ & N.S. \\
\hline $\mathrm{AMH}(\mathrm{ng} / \mathrm{mL})$, mean $\pm \mathrm{SD}$ & $0.45 \pm 0.16$ & $2.99 \pm 0.11$ & $<0.0001$ \\
\hline $\begin{array}{l}\text { Total doses of HMG/ FSH (IU), } \\
\text { mean } \pm \text { SD }\end{array}$ & $1487 \pm 113$ & $1816 \pm 66.5$ & 0.013 \\
\hline $\begin{array}{l}\text { Estrogen value of before hCG } \\
(\mathrm{pg} / \mathrm{mL}) \text {, mean } \pm \mathrm{SD}\end{array}$ & $481 \pm 86.1$ & $927 \pm 60.4$ & $<0.0001$ \\
\hline $\begin{array}{l}\text { Progesterone value of before hCG } \\
(\mathrm{ng} / \mathrm{mL}), \text { mean } \pm \text { SD }\end{array}$ & $0.35 \pm 0.04$ & $0.49 \pm 0.03$ & 0.0076 \\
\hline $\begin{array}{l}\text { No. of oocytes retrieved, } \\
\text { mean } \pm \text { SD }\end{array}$ & $1.96 \pm 1.08$ & $6.83 \pm 0.83$ & $<0.0001$ \\
\hline $\begin{array}{l}\text { Frequency of oocyte retrievals per } \\
\text { patient, mean } \pm \text { SD }\end{array}$ & $2.43 \pm 0.52$ & $1.98 \pm 0.38$ & N.S. \\
\hline $\begin{array}{l}\text { Cumulative pregnancy rate per } \\
\text { patient }\end{array}$ & $14.6 \%(7 / 48)$ & $19.8 \%(37 / 96)$ & 0.0038 \\
\hline $\begin{array}{l}\text { Cumulative live birth rate per } \\
\text { patient }\end{array}$ & $6.3 \%(3 / 48)$ & $20.8 \%(20 / 96)$ & 0.0292 \\
\hline
\end{tabular}

*Low AMH, AMH $<1 \mathrm{ng} / \mathrm{mL}$. **Normal AMH group, AMH $\geq 1 \mathrm{ng} / \mathrm{mL}$.

$\mathrm{AMH}=$ anti-Müllerian hormone; IVF=in vitro fertilization; N.S.= not significant.

Table 3. Comparison of live births and non-live births in the younger low group.

\begin{tabular}{|c|c|c|c|}
\hline & $\begin{array}{c}\text { Live birth } \\
\text { ( } \mathrm{n}=11 \text { patients })\end{array}$ & $\begin{array}{c}\text { Non-live birth } \\
(n=17 \text { patients })\end{array}$ & $\boldsymbol{p}$ \\
\hline Age $(y)$, mean \pm SD & $35.40 \pm 1.76$ & $35.4 \pm 1.46$ & N.S. \\
\hline No. of oocytes retrieved, mean \pm SD & $2.00 \pm 2.30$ & $3.00 \pm 1.63$ & N.S. \\
\hline $\begin{array}{l}\text { Frequency of oocyte retrievals per } \\
\text { patient, mean } \pm \text { SD }\end{array}$ & $3.45 \pm 1.18$ & $2.05 \pm 0.95$ & 0.035 \\
\hline No. of fertilized oocytes, mean $\pm S D$ & $2.00 \pm 1.99$ & $2.00 \pm 1.54$ & N.S. \\
\hline Blastocyst transfer rate & $63.6 \%(7 / 11)$ & $11.8 \%(2 / 17)$ & 0.010 \\
\hline Fresh embryo transfer & $66.7 \%(2 / 3)$ & $100 \%(1 / 1)$ & N.S. \\
\hline Thawed embryo transfer & $62.5 \%(5 / 8)$ & $6.3 \%(1 / 16)$ & 0.04 \\
\hline AMH levels $(\mathrm{ng} / \mathrm{mL})$, mean $\pm \mathrm{SD}$ & $0.57 \pm 0.18$ & $0.45 \pm 0.15$ & N.S. \\
\hline
\end{tabular}

$\mathrm{AMH}=$ anti-Müllerian hormone; N.S. = not significant.

and others reporting the lack thereof (Fanchin et al., 2007; Peñarrubia et al., 2005; Fiçicioglu et al., 2006; Smeenk et al., 2007). A recent meta-analysis examined the association between AMH and IVF treatment cycles with pregnancy and implantation rates, with results demonstrating only a weak association (Tal et al., 2015). Conversely, in the literature focusing on live births, a weak but relevant relationship (Tal et al., 2018) was reported; however, no consensus has been achieved.

Our findings indicate that AMH was not associated with live births in the younger group. However, the rate of live births and pregnancies was significantly higher in the older normal AMH group ( $A M H \geq 1.0 \mathrm{ng} / \mathrm{mL}$ ). There have been reports associating $\mathrm{AMH}$ with live births and pregnancy rates in patients aged 38 years or older (Kato et al., 2015), which is consistent with the results of this study. The total HMG dose was significantly higher in the normal AMH group than in the low AMH group. Furthermore, the total HMG dose in the low AMH group was relatively lower owing to the implementation of a mild-stimulation protocol. Likewise, estrogen levels were lower in the low AMH group.
Patients categorized into the younger low AMH group were few, and the number of patients in this study was also small, such that a multivariate analysis was not feasible. Therefore, a univariate analysis was instead conducted to compare patients who achieved live births with patients who did not. The rate of blastocyst transfer and the mean frequency of oocyte retrievals per patient were significantly associated with the characteristics of patients with live births in the younger low AMH group. Sefrioui et al. (2019) retrospectively examined IVF and pregnancy outcomes of 390 patients in the low AMH group $(<0.4 \mathrm{ng} / \mathrm{mL})$ and 352 patients in the normal AMH group $(1.3-2.6 \mathrm{ng} / \mathrm{mL})$. In patients aged $\leq 35$ years, the clinical pregnancy rates in the low AMH group and the normal AMH group were $27 \%$ and $41 \%$, respectively. This indicates that younger women with low AMH have a good chance of getting pregnant (Sefrioui et al., 2019). In this study, the younger low AMH group had similar pregnancy rates and live birth rates compared with the younger normal AMH group.

Our report suggests that young people with low AMH have the potential to become pregnant if they can obtain 
blastocysts with frequent oocyte retrievals. Examination of the blastocyst transfer rates in fresh and thawed embryo transfers in the live birth and non-live birth groups in a subset analysis revealed significantly higher blastocyst transfer rates in the live birth group.

This study has some limitations. First, this study is retrospective in nature. Second, the type of ART treatment included both fresh embryo and thawed embryo transfers, which may have introduced bias based on the type of treatment. Further studies with large sample sizes are warranted to determine this clinically important issue and to strengthen the findings of our study.

\section{CONCLUSION}

The live birth rate of younger patients with low $\mathrm{AMH}$ levels was equivalent to that of younger patients with normal AMH values. In addition, the likelihood of achieving a live birth increased with the number of blastocyst transfers. Thus, aggressive treatment intervention and continuation are considered acceptable.

\section{CONFLICT OF INTEREST}

There are no conflicts of interest to declare.

\author{
Corresponding author: \\ Maho Miyagi \\ Department of Obstetrics and Gynecology \\ Graduate School of Medicine \\ University of the Ryukyus \\ Nishihara, Okinawa, Japan. \\ E-mail: h097387@med.u-ryukyu.ac.jp
}

\section{REFERENCES}

Baker VL, Gracia C, Glassner MJ, Schnell VL, Doody K, Coddington CC, Shin SS, Marshall LA, Alper MM, Morales AJ, Pavone ME, Behera MA, Zbella EA, Shapiro BS, Straseski JA, Broyles DL. Multicenter evaluation of the Access AMH antimüllerian hormone assay for the prediction of antral follicle count and poor ovarian response to controlled ovarian stimulation. Fertil Steril. 2018;110:506-13.e3. PMID: 29960708 DOI: 10.1016/j.fertnstert.2018.03.031

Eldar-Geva T, Ben-Chetrit A, Spitz IM, Rabinowitz R, Markowitz E, Mimoni T, Gal M, Zylber-Haran E, Margalioth EJ. Dynamic assays of inhibin B, anti-Mullerian hormone and estradiol following FSH stimulation and ovarian ultrasonography as predictors of IVF outcome. Hum Reprod. 2005;20:3178-83. PMID: 16113044 DOI: 10.1093/humrep/dei203

Fanchin $\mathrm{R}$, Mendez Lozano DH, Frydman N, Gougeon A, Frydman R, Gougeon A, di Clemente N, Frydman R, Taieb J. Anti-Müllerian hormone concentrations in the follicular fluid of the preovulatory follicle are predictive of the implantation potential of the ensuing embryo obtained by in vitro fertilization. J Clin Endocrinol Metab. 2007;92:1796802. PMID: 17327387 DOI: $10.1210 /$ jc.2006-1053

Fiçicioglu C, Kutlu T, Baglam E, Bakacak Z. Early follicular antimüllerian hormone as an indicator of ovarian reserve. Fertil Steril. 2006;85:592-6. PMID: 16500324 DOI: $10.1016 /$ j.fertnstert.2005.09.019
Hansen KR, He AL, Styer AK, Wild RA, Butts S, Engmann L, Diamond MP, Legro RS, Coutifaris C, Alvero R, Robinson RD, Casson P, Christman GM, Huang H, Santoro N, Eisenberg E, Zhang $\mathrm{H}$; Eunice Kennedy Shriver National Institute of Child Health and Human Development Reproductive Medicine Network. Predictors of pregnancy and live-birth in couples with unexplained infertility after ovarian stimulation-intrauterine insemination. Fertil Steril. 2016;105:1575-83.e2. PMID: 26949110 DOI: $10.1016 /$ j.fertnstert.2016.02.020

Kato N, Iwase A, Sugita A, Goto $M$, Nakahara T, Nakamura T, Kondo M, Osuka S, Mori M, Saito A, Kikkawa F. Anti-Müllerian hormone as a possible predictor of fecundability in subfertile women over 38 years: a retrospective cohort study. Gynecol Endocrinol. 2015;31:22-5. PMID: 25030844 DOI: 10.3109/09513590.2014.943720

La Marca A, Giulini S, Tirelli A, Bertucci E, Marsella T, Xella S, Volpe A. Anti-Müllerian hormone measurement on any day of the menstrual cycle strongly predicts ovarian response in assisted reproductive technology. Hum Reprod. 2007;22:76671. PMID: 17071823 DOI: 10.1093/humrep/del421

La Marca A, Sighinolfi G, Radi D, Argento C, Baraldi E, Artenisio AC, Stabile G, Volpe A. Anti-Mullerian hormone $(\mathrm{AMH})$ as a predictive marker in assisted reproductive technology (ART). Hum Reprod Update. 2010;16:113-30. PMID: 19793843 DOI: 10.1093/humupd/dmp036

Nelson SM, Yates RW, Fleming R. Serum anti-Müllerian hormone and FSH: prediction of live birth and extremes of response in stimulated cycles--implications for individualization of therapy. Hum Reprod. 2007;22:2414-21. PMID: 17636277 DOI: $10.1093 /$ humrep/dem204

Peñarrubia J, Fábregues F, Manau D, Creus M, Casals G, Casamitjana R, Carmona F, Vanrell JA, Balasch J. Basal and stimulation day 5 anti-Mullerian hormone serum concentrations as predictors of ovarian response and pregnancy in assisted reproductive technology cycles stimulated with gonadotropin-releasing hormone agonist--gonadotropin treatment. Hum Reprod. 2005;20:915-22. PMID: 15665015 DOI: 10.1093/humrep/deh718

Sefrioui O, Madkour A, Aboulmaouahib S, Kaarouch I, Louanjli N. Women with extreme low AMH values could have in vitro fertilization success. Gynecol Endocrinol. 2019;35:170-3. PMID: 30324831 DOI: $10.1080 / 09513590.2018 .1505850$

Silberstein T, MacLaughlin DT, Shai I, Trimarchi JR, Lambert-Messerlian G, Seifer DB, Keefe DL, Blazar AS. Mullerian inhibiting substance levels at the time of HCG administration in IVF cycles predict both ovarian reserve and embryo morphology. Hum Reprod. 2006;21:159-63. PMID: 16123085 DOI: 10.1093/humrep/dei270

Smeenk JM, Sweep FC, Zielhuis GA, Kremer JA, Thomas $C M$, Braat DD. Antimüllerian hormone predicts ovarian responsiveness, but not embryo quality or pregnancy, after in vitro fertilization or intracyoplasmic sperm injection. Fertil Steril. 2007;87:223-6. PMID: 17081531 DOI: 10.1016/j. fertnstert.2006.06.019 
Tal R, Tal O, Seifer BJ, Seifer DB. Antimüllerian hormone as predictor of implantation and clinical pregnancy after assisted conception: a systematic review and meta-analysis. Fertil Steril. 2015;103:119-30.e3. PMID: 25450298 DOI: 10.1016/j.fertnstert.2014.09.041
Tal R, Seifer DB, Wantman E, Baker V, Tal O. Antimüllerian hormone as a predictor of live birth following assisted reproduction: an analysis of 85,062 fresh and thawed cycles from the Society for Assisted Reproductive Technology Clinic Outcome Reporting System database for 2012-2013. Fertil Steril. 2018;109:25865. PMID: 29331235 DOI: 10.1016/j.fertnstert.2017.10.021 